\title{
ANALYSIS OF DIFFERENTIALLY EXPRESSED GENES RELATED TO INTRAMUSCULAR FAT AND CHEMICAL COMPOSITION IN DIFFERENT BREEDS OF CHICKEN
}

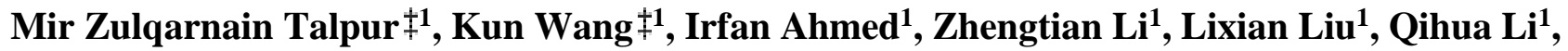 \\ Tengfei Dou1, Dahai $\mathrm{Gu}^{2}$, Zhiqiang $\mathrm{Xu}^{2}$, Hua Rong${ }^{1}$, Shanrong Wang ${ }^{1}$, Zhibin Cheng ${ }^{1}$, Ying \\ Huang ${ }^{1}$, Xiaobo Chen1, Huiquan Tong ${ }^{1}$, Sumei Zhao', Guiping Zhao ${ }^{3}$, Zhengchang Su${ }^{4}$, \\ Changrong Ge ${ }^{1, *}$ and Junjing Jia ${ }^{1, *}$
}
${ }^{1}$ Yunnan Provincial Key Laboratory of Animal Nutrition 650201, Yunnan Province, People's Republic of China; ${ }^{2}$ Department of Food Science, Yunnan Agricultural University, Kunming 650201, Yunnan Province, People's Republic of China; ${ }^{3}$ Institute of Animal Sciences, Chinese Academy of Agricultural Sciences, Beijing 100193, People's Republic of China; ${ }^{4}$ Department of Bioinformatics and Genomics, College of Computing and Informatics, the University of North Carolina at Charlotte, Charlotte, USA \$These authors contributed equally to this work. "Corresponding author's e-mail: gcrzal@126.com; junjingli2009@ hotmail.com

\begin{abstract}
Chemical composition traits, for instance, intramuscular fat (IMF) are an important meat quality trait. However, the molecular mechanisms related to IMF deposition in skeletal muscle have not previously been discussed for the native Yunnan (Wuding, Mini, and Wuliangshan) chicken breeds. In order to determine important discrepancies in IMF content, the chemical composition, and phenotypical variations in the gene expression of different breeds, five genes related to fat metabolism were analyzed in the muscle tissues of twenty-week-old native Yunnan breeds and the commercial broiler breed through quantitative reverse transcription PCR (qRT-PCR). The results were a clear statement that breeds had significant effects on LPL, UCP, FAS, FATP1, and PPAR-a gene expression. Higher $(\mathrm{P}<0.05)$ LPL gene, UCP gene, and FAS gene expression were observed in the muscles of the Wuding chicken. In comparison, higher $(\mathrm{P}<0.05)$ muscle FATPl gene expression was found in the Mini chicken. The levels of PPAR- $a$ gene (PPAR-a) mRNA were greatest $(\mathrm{P}<0.05)$ in the Wuding, moderate $(\mathrm{P}<0.05)$ in the Mini, and lowest in the Wuliangshan and the broiler. Chemical composition exhibited the lowest IMF content in the broiler thigh and breast muscle. In the thigh muscles, the Wuding chicken had the highest IMF content, while the Mini chicken had higher crude protein levels and ash content. In comparison, the breast muscles of the Wuliangshan had higher crude fat, protein, and ash content followed by those of the Wuding and the Mini. Variations in gene expression in different breeds and their relationship to chemical composition could contribute to the distinct fatty phenotype and characteristic flavor of native Yunnan chicken. The identification of variations in gene expression could facilitate targeted sequencing and genotyping efforts for advanced studies.
\end{abstract}

Keywords: Yunnan chicken breed, intramuscular fat, ash, genes, chemical composition of meat.

\section{INTRODUCTION}

Poultry production has increased noticeably to meet consumers' demand. Therefore, producers' desire to achieve commercial profit requirements. The advancement of desirable traits has led to the achievement of undesirable taste and meat quality; as a result, consumers are searching for alternatives that will give them superior-tasting chicken meat (Berri et al., 2001; Du et al., 2010).

Chemical composition and carcass traits, for instance, fat, protein, and ash, are important economic traits for poultry because they are associated with meat production efficiency. Intramuscular fat (IMF) plays a key role in meat quality. IMF deposition is generally distributed in the epimysium, perimysium, and endomysium that positioned between muscle cells and fibers. The meat with high IMF levels had favorable meat qualities such as improved tenderness, juiciness, flavor, and good water-holding capacity (Fernandez et al., 1999). So IMF is a factor through which meat quality could potentially be manipulated (Cui et al., 2012; Ros-Freixedes et al., 2014). Molecular mechanisms associated with meat quality have previously been examined in livestock (Moreno-Sánchez et al., 2010; Zhao et al., 2011) and mammals such as Laiwu (Hu et al., 2008) and Jinhua (Guo et al., 2011), which are local Chinese pig breeds. It is common knowledge that IMF deposition is associated with potential candidate genes such as H-FABP (Nechtelberger $e t$ al., 2001) and Sirt1 (Moynihan and Imai, 2006). So far, in 
comparison to knowledge regarding monogastric mammals, there is little knowledge regarding the molecular mechanisms associated with better taste and meat quality in the Yunnan chicken breeds (Wuding, Mini, and Wuliangshan). Native chicken breeds are famous for their favorable characteristics, including better disease resistance, excellent meat taste, and flavor (Fanatico et al., 2005). Thus, the consumption of native chicken breeds have been growing in East Asian countries and Europe regardless of their comparatively higher prices (Yang and Jiang, 2005). The Wuding, Mini, and Wuliangshan are native chicken breeds from Yunnan province of China, and Arbor Acres (AAB) is a fast-growing commercial broiler breed. Researchers agree that, though local chicken has less efficient growth performances than commercial broilers, their meat is more desirable in quality (Lewis et al., 1997; Castellini et al., 2002).

The more delicious taste and better meat quality of native chicken breeds than those of commercial broilers provide the basis for the comparison of the gene expression and meat quality of native breeds and commercial broilers. Therefore, the discovery and characterization of differentially expressed genes between the native and broiler chicken would be a useful tool for the identification of the IMF regulators in the muscles of chicken. It is possible that the identification of some genes that have expression differences associated with fat has occurred. The aim of this study is to produce information regarding the genetic background of the unique fatty phenotype, and taste of Wuding, Mini, and Wuliangshan native chicken breeds.

In the present study, the characterization of mRNA expression profiles in the skeletal muscles of 20-week-old Wuding, Mini, Wuliangshan, and broiler chicken was performed by selection, using 5 candidate genes that could affect IMF deposition. Then the changes in expression of the five candidate genes were analyzed using qRT-PCR to identify their relationship with IMF deposition, and chemical composition in the skeletal muscle of phenotypically different native chicken breeds.

\section{MATERIALS AND METHODS}

Experimental design and dietary nutrient level: The diet content was consistent with the formulation recommended by the Chinese Chicken Feeding Standard (2004) recommendations. A total of 200 one-day-old chicks, including 50 Wuding chicks, 50 Mini, 50 Wuliangshan, and 50 broiler chicks (Avian) as a control were used in this study for 20 weeks. The composition of diets is provided in Table 1. Feeding and management: The chickens had free access to feed and water during the entire rearing period. The chicks were reared in an environmentally controlled room. The brooding temperature was maintained at $35^{\circ} \mathrm{C}$ for the first 2 days, and then decreased gradually to $22^{\circ} \mathrm{C}$ until 30 days and there after maintained until the end of the experiment. At 30 days old, the chickens were randomly allocated to individual metabolism cages in an enclosed room, with ambient temperatures varying from $21-24^{\circ} \mathrm{C}$, under the artificial fluorescent light on a light-dark cycle of 12:12 h.

Table 1. Compositions and nutrient levels in the diets.

\begin{tabular}{lrc}
\hline Diet composition (\%) & Chick diet & Adult chicken diet \\
\hline Corn & 64.70 & 67.90 \\
Soy protein & 30.20 & 18.10 \\
Wheat bran & 0.00 & 10.00 \\
Soya oil & 1.10 & 0.00 \\
Calcium hydrogen & 1.50 & 1.50 \\
phosphate & & \\
Stone meal & 0.70 & 0.60 \\
Milling flour & 0.41 & 0.46 \\
Met & 0.08 & 0.07 \\
Salt & 0.35 & 0.35 \\
Compound premix 1 & 1.00 & 1.00 \\
Total & 100.00 & 100.00 \\
Nutrient levels & & \\
Metabolism energy & 2900.00 & 2780.00 \\
(kcal/kg) & & \\
Crude protein (\%) & 19.30 & 15.50 \\
Calcium (\%) & 0.85 & 0.80 \\
Total phosphorus (\%) & 0.61 & 0.64 \\
Available phosphorus $(\%)$ & 0.37 & 0.37 \\
Salt (\%) & 0.37 & 0.37 \\
Lys (\%) & 0.98 & 0.75 \\
Met (\%) & 0.39 & 0.32 \\
Methionine + Cystinol (\%) & 0.73 & 0.60 \\
\hline Suppied per kilogram of & & \\
\hline
\end{tabular}

${ }^{1}$ Supplied per kilogram of diet: vitamin A, 15,000 IU; vitamin D3, $3300 \mathrm{IU}$; vitamin $\mathrm{E}, \quad 62.5 \mathrm{mg}$; vitamin $\mathrm{K}, 3.6 \mathrm{mg}$; vitamin B1, $3 \mathrm{mg}$; vitamin B2, $9 \mathrm{mg}$; vitamin B6, $6 \mathrm{mg}$; vitamin B12, $0.03 \mathrm{mg}$; niacin, $60 \mathrm{mg}$; calcium pantothenate, $18 \mathrm{mg}$; folic acid, 1.5 mg; biotin, $0.36 \mathrm{mg}$; choline chloride, $600 \mathrm{mg}$; Fe, $80 \mathrm{mg}$; Cu, 12 $\mathrm{mg}$; Zn, $75 \mathrm{mg}$; Mn, $60 \mathrm{mg}$; I, $0.35 \mathrm{mg}$; Se, $0.15 \mathrm{mg}$; growth promoting agent, $30 \mathrm{mg}$; and antioxidant, $100 \mathrm{mg}$

Animals: Four phenotypically different breeds were selected: Wuding, Mini, Wulingshan and commercial broiler. The four breeds were fed under the same conditions (ad-libitum feeding, the same feed stuff) to 20 weeks of age. Selection of chickens is made on same age; because gene expression and protein levels can be influenced by age (Ren et al., 2002; Christoffersen et al., 2010). All animals used in this study were permitted from Animal Care Committee, Yunnan Agricultural University (Yunnan, China). Chickens were euthanized with minimum suffering.

Sample collection: Twelve birds of similar body weight were selected from each breed and sacrificed for tissue collection. Thigh and breast muscle samples were excised, preserved in cryopreservation tubes in liquid nitrogen $\left(-196^{\circ} \mathrm{C}\right)$. The meat samples from the thigh and breast muscles were taken, dried, ground, and then analyzed for percentage crude protein, fat and total ash. Standard methods (AOAC 2011) were used for 
Intramuscular fat genes expression in chicken

Table 2. Primer name sequencing, annealing temperature and product length.

\begin{tabular}{|c|c|c|c|}
\hline Primer name & Primer sequence & Annealing temp. $\left({ }^{\circ} \mathrm{C}\right)$ & Product length (bp) \\
\hline \multirow[t]{2}{*}{ FAS } & F: TGGTTGACTGCCACCAATTG & 58.2 & 213 \\
\hline & R: ACCCCACTTTCCATCACGAT & & \\
\hline \multirow[t]{2}{*}{ FATPl } & F: TCACCACCAACTCAGATCCC & 58.2 & 183 \\
\hline & R: CGGAAGGCAGTTGTAGAGGA & & \\
\hline \multirow[t]{2}{*}{$L P L$} & F: CTGGTGGGAAAGGATGTTGC & 60.0 & 229 \\
\hline & R: CAAAGTCAGCATCATCCGGG & & \\
\hline \multirow[t]{2}{*}{$P P A R-\alpha$} & F: TTCGAATCTTCCACTGCTGC & 59.2 & 186 \\
\hline & R: CCAGCATCCCATCTTTGTTCA & & \\
\hline \multirow[t]{2}{*}{$U C P$} & F: ACAACGTCCCCTGTCACTTC & 56.0 & 158 \\
\hline & R: ATGAACATCACCACGTTCCA & & \\
\hline
\end{tabular}

analysis. Briefly, for determination of Crude protein, Kjeldahl method was used. Lipid contents were determined through soxlet apparatus. Samples were extracted using diethyl ether, expressed as percentages of the dry weight.

qRT-PCR analysis: The primers were designed on the basis of published cDNA sequences, the LPL, FATP1, PPAR-a, UCP, FAS and $18 S$ genes (http://www.ncbi.nlm.nih.gov) using GENETOOL software (BioTools, Alberta, Canada) for isolation of total RNA TRIzol Reagent (Thermo Fisher Scientific, USA) and 1-bromo-3-chloropropane (VWR International, USA) were used. Three isolations were carried out for every experimental animal and for each tissue. Samples (150-200 mg) were processed with Tissue Lyser LT (Qiagen, Germany) for each isolation. The concentration of RNA was determined by means of a NanoDrop 2000 spectrophotometer (Thermo Fisher Scientific). The integrity of RNA diluted in DEPC-treated nuclease-free water was verified by agarose gel electrophoresis and ethidium bromide staining. To avoid contamination of DNA, isolated RNA was treated with RQ1 RNase-free DNase (Promega, USA) as recommended by manufacturers. Reverse Transcription was performed using an iScript cDNA synthesis kit (Bio-Rad, USA) on each $1 \mu \mathrm{g}$ of total RNA sample. Gene expression was quantified by qPCR using SsoFast EvaGreen Supermix (Bio-Rad) and the 2-11Ct method. Reactions were performed in triplicates on a CFX96 real-time PCR detection system (Bio-Rad) using clear plates. $\beta$-actin $(A C T B)$ was used as a reference gene (Luo et al., 2009). The sequences of the primers, product lengths, accession numbers, relevant annealing temperatures, and efficiency of PCRs are shown in Table 2. The efficiency of each gene was determined by 10 fold dilution series ("standards") of the PCR products. Every analyzed and reference gene contained no template controls (NTCs). The NTCs considered negative with threshold cycles above 35, as quantitation cycles were always prior to this cycle. Following the last cycle, validation of amplification product was performed through melt curve analysis. Expression data were analyzed using SPSS software. Oneway ANOVA (Tukey's) test in SPSS v.16 for Windows (SPSS Inc.) difference in means $P<0.05$ were considered statistically significant.

\section{RESULTS AND DISCUSSION}

The chemical compositions of breast and thigh meat are presented in Table 3. In our study, different breeds had a clear effect on the chemical composition of meat. For breast meat of four breeds, the intramuscular fat (IMF), ash, and protein contents were in the ranges of 1.22 to $1.91,0.53$ to 0.91 , and 23.74 to $27.97 \mathrm{~g} / 100 \mathrm{~g}$, respectively. For thigh meat of four breeds, the intramuscular fat (IMF), ash, and protein contents ranged from 1.28 to $1.51,1.07$ to 2.43 , and 23.49 to 26.40 $\mathrm{g} / 100 \mathrm{~g}$, respectively. In the present study, the native breeds of Wuliangshan, Wuding and Mini chicken had higher fat, ash, and crude protein content than the broilers. In comparison, the IMF content of the broiler's breast and thigh was lower $(\mathrm{P}>0.05)$ than that of the Wuding, Mini, and Wuliangshan chicken.

Table 3. Chemical composition of thigh muscle and breast muscle samples of Wuliangshan, Wuding, Mini and broiler chicken at 20 weeks of age $($ mean \pm S.E).

\begin{tabular}{lrr}
\hline Index & Breast Muscle & \multicolumn{1}{l}{ Thigh Muscle } \\
\hline \multicolumn{2}{l}{ Wuliangshan Chicken } & \\
Crude protein (\%) & $27.971 \pm 1.902^{\mathrm{a} 1}$ & $23.494 \pm 0.974^{\mathrm{c} 2}$ \\
Crude fat (\%) & $0.916 \pm 0.536^{\mathrm{a} 2}$ & $1.682 \pm 0.463^{\mathrm{c} 1}$ \\
Crude ash (\%) & $1.917 \pm 0.281^{\mathrm{a} 1}$ & $1.324 \pm 0.087^{\mathrm{b} 2}$ \\
Mini Chicken & & \\
Crude protein (\%) & $27.754 \pm 1.529^{\mathrm{a} 1}$ & $26.404 \pm 2.026^{\mathrm{a} 2}$ \\
Crude fat (\%) & $0.619 \pm 0.371^{\mathrm{c} 2}$ & $1.835 \pm 1.328^{\mathrm{b} 1}$ \\
Crude ash (\%) & $1.691 \pm 0.170^{\mathrm{b} 1}$ & $1.512 \pm 0.115^{\mathrm{a} 2}$ \\
Wuding Chicken & & \\
Crude protein (\%) & $26.607 \pm 1.740^{\mathrm{b} 1}$ & $23.847 \pm 1.856^{\mathrm{d} 2}$ \\
Crude fat (\%) & $0.806 \pm 0.342^{\mathrm{b} 2}$ & $2.437 \pm 0.997^{\mathrm{a} 1}$ \\
Crude ash (\%) & $1.590 \pm 0.236^{\mathrm{c} 1}$ & $1.384 \pm 0.108^{\mathrm{b} 2}$ \\
Broiler Chicken & & \\
Crude protein (\%) & $23.746 \pm 1.779^{\mathrm{c} 2}$ & $25.044 \pm 2.632^{\mathrm{b} 1}$ \\
Crude fat (\%) & $0.533 \pm 0.149^{\mathrm{d} 2}$ & $1.078 \pm 0.586^{\mathrm{d} 1}$ \\
Crude ash (\%) & $1.224 \pm 0.192^{\mathrm{d} 2}$ & $1.282 \pm 0.160^{\mathrm{c} 1}$ \\
\hline
\end{tabular}

a,b Mean figure bearing different superscripts row wise differ significantly(p>0.05); 1,2 mean figure of two consecutive 
parameters (between type of muscles) bearing different superscripts column wise differ significantly ( $\mathrm{p}>0.05)$.

The comparison of the breeds revealed that thigh muscle fat content was higher in the Wuding chicken (2.43), whereas intermittent in the Mini (1.83), Wuliangshan chicken (1.68), and lowest in the broiler (1.07). Moreover, IMF content in breast muscle was highest in the Wuliangshan (0.91) and the Wuding (0.80), while intermediate in the Mini (0.61), and lowest in the broiler (0.53). It is already accepted that IMF content plays a key role in determining the good flavor, juiciness, and improved tenderness of meat (Fernandez et al., 1999). In view of the fact that genes and the environment could influence the IMF content of meat (Dikeman et al., 2005), the present study took care to ensure that the IMF level was determined under similar conditions (for instance, slaughter age, muscle type, gender, and feeding (Dodson et al., 2010; Geldenhuys et al., 2013; Anderson et al., 2015) for minimum variation. So breed was retained as the major source of the significant differences observed. In addition, protein content was higher in the Mini chicken (26.40) followed by the broiler (25.04), the Wuding chicken (23.84), and the Wuliangshan chicken (23.49). Furthermore, the crude ash produced was higher in quantity for the Mini (1.51), followed by the Wuding (1.38) and the Wuliangshan (1.32), and lowest for the broiler (1.28). In the breast muscles, crude protein and ash content were highest $(\mathrm{P}<0.05)$ for the Wuliangshan chicken $(27.97,1.91)$ and the Mini chicken $(27.75,1.69)$, intermediate in the Wuding chicken $(26.60,1.59)$, and lowest in the broiler $(23.74,1.22)$. Similarly in a previous study that compared native Korean chicken meat and broiler meat. Choe et al. (2010) found that the native Korean chicken had higher crude protein and ash content than the broiler. Moreover, in our study, the ash content was higher $(\mathrm{P}<0.05)$ in the breast and thigh muscles of the native chicken than in the broiler meat samples. Choe et al. (2010) found higher (0.96\%) crude ash content in the native Korean chicken than in the broiler $(0.47 \%)$. Furthermore, (Liu and Niu, 2008) found higher ash content in the breast and thigh muscles of native quality chicken. Intra-breed comparisons of the thigh and breast muscle, protein content, and ash content showed higher $(\mathrm{P}<0.05)$ values in the breast muscles than in the thigh meat of the Wuding, Mini, and Wuliangshan. By contrast, for the broiler, higher values were obtained in the thigh than in the breast muscle. Moreover, IMF content was higher in the thigh muscles than in the breast muscles of all the breeds. Contrary to the protein and ash content, the IMF content was lower in the breast muscles that it was in the thigh muscles. The results of (Huda et al., 2011) for duck meat and those of (Jaturasitha et al., 2008) for chicken meat were similar to those of our study. The present study revealed that, under the same rearing conditions, the Wuding, Mini, and Wuliangshan had superior meat quality to the broiler in terms of IMF content, ash, and protein content. Moreover, it indicated that these 4 chicken breeds provided a good model for studying IMF deposition.
The results were a clear statement that breeds had significant effects on LPL, UCP, FAS, FATP1, and PPAR-a gene expression. Higher $(\mathrm{P}<0.05) \mathrm{LPL}$ gene, UCP gene, and FAS gene expression were observed in the muscles of the Wuding than in those of the Mini, the Wuliangshan, and the broiler. In comparison, higher $(\mathrm{P}<0.05)$ muscle FATP1 gene expression was found in the Mini chicken. The levels of PPAR-a gene (PPAR-a) mRNA were greatest $(\mathrm{P}<0.05)$ in the Wuding, while moderate $(\mathrm{P}<0.05)$ in the Mini, and lowest in the Wuliangshan and the broiler.

Lipoprotein lipase gene expression (LPL): Differences observed in meat quality have been related to lipoprotein lipase (LPL) gene expression. Researchers agree that IMF deposition is a major factor that affects meat quality. Therefore, they have succeeded in identifying functional genes linked to IMF deposition in pigs (Shan et al., 2006) and chickens (Sato et al., 1999). In our study, we differentially compared the mRNA of the LPL gene in the muscle tissues of native Yunnan chickens and commercial broiler chickens. The muscle expression of LPL was remarkably higher $(\mathrm{P}<0.05)$ in the Wuding chicken than in the Mini, the Wuliangshan, and the broiler. It was also higher in the Mini chicken than it was in the Wuliangshan and the broiler, but the difference was not significant (Fig. 1).

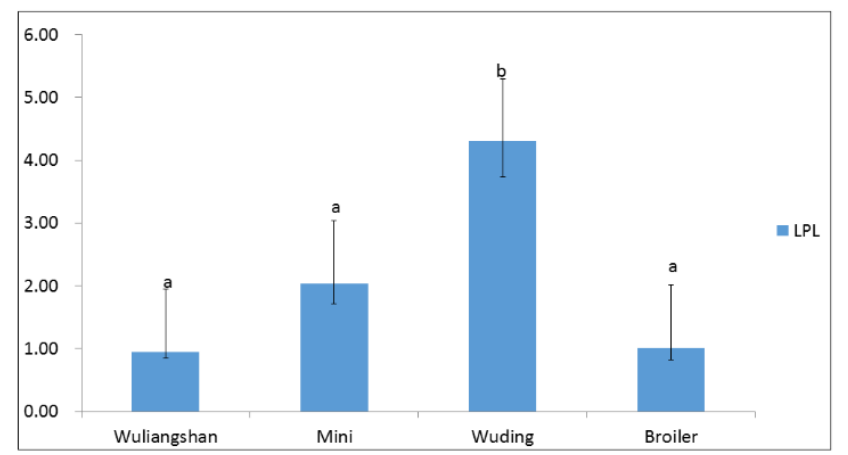

Figure 1. Changes of different chicken breeds' muscle LPL gene mRNA expression: Photographs showing qPCR analysis of LPL expression of three native chickens and one broiler at the age of 20 weeks. Wuding chickens had higher gene expression. Data are presented as means \pm standard error. The difference marked with lowercase letters indicate significant differences $(\mathrm{P}<0.05)$.

LPL is a water-soluble enzyme that fat cells, skeletal muscle cells, and myocardial cells synthesize and secrete, but mainly catalytic chylous particles and very low-density lipoproteins synthesize and secrete them too. LPL produces fatty acids and glycerol from triglycerides for cellular use and is a major enzyme in fat metabolism (Beisiegel and Heeren, 1997; Mead et al., 2002). Lipoprotein lipase (LPL) catalyzed the triglycerides' hydrolysis of lipoproteins, reduced the 
activity or deficiency of LPL, and increased lipemia and triglyceridemia (Bensadoun, 1991). The results of Hocquette et al. (1998), which indicated that, for muscle growth, LPL could amplify fat storage or supply energy storage in the shape of fatty acids, supported this hypothesis. Ren et al. (2002) suggested that LPL mRNA gene expression in the fat deposit was greater and associated with the fat content in dairy cattle. It was previously observed that the chronic infusion of LPL monoclonal antibodies against abdominal adipose tissue reduced the abdominal fat pad weight in chickens (Sato et al., 1999). These results demonstrated that the chicken's LPL gene played an essential role in fat accumulation in adipose tissue. In our study, the LPL gene varies significantly with breed, and fat content. For instance, the Wuding and Mini chicken had higher fat contents in the thigh muscles and higher expressions of the LPL gene than the Wuliangshan and broiler. Moreover, consistent with the present results were the findings (Griffin et al., 1987; Kouba et al., 1995) that total LPL gene regulation in abdominal fat correlated with fat pad weight in chicken, turkey, and other birds. LPL gene activity in the adipose tissue was less responsive to the nutritional state (Hermier et al., 1984). In the present study, the conclusion was that the interaction between lipoprotein lipase genes was associated with IMF content in chickens.

FATP1 gene expression: Fatty acid transport protein 1 (FATP1) is one of the major genes that affect the fat content of the body (Binnert et al., 2000). It shows higher expression in skeletal muscles and adipose tissues (Schaffer and Lodish, 1994; Hirsch et al., 1998). It is already recognized that FATP1 genes play an important role in fatty acid uptake (Lobo et al., 2007). The FATP1 gene has a close relationship with obesity due to its role in mediating fatty acid uptake; thus, it is considered to be an important candidate gene (Doege and Stahl, 2006). Because it can indirectly influence lipid deposition and the lipid profile under the regulation of skeletal muscle fatty acid uptake and metabolism, the determination of its expression may be important for the genetic improvement of meat traits (Pohl et al., 2004). The results of our efforts to clarify the mechanisms of the gene for different levels of expression showed that FATP1 genes were expressed in all breeds. Based on the results for FATP1 gene expression, higher $(\mathrm{P}<0.05)$ expression was detected in the muscle tissues of the Mini chicken than in those of the Wuliangshan, the Wuding, and the broiler (Fig. 2). Davail et al. (2000) found that there were obvious breed-related or species-related differences in the process of lipogenesis among different poultry breeds; they also found that breed had an effect on lipogenesis, probably under genetic control. The FATP1 gene had a relationship with intramuscular fat deposition (Hatch et al., 2002) and it was possibly connected to the protein contents of muscle. Fatty acid transport proteins are major transmembrane proteins in cells that increase the uptake of long-chain and very long-chain fatty acids (Schaffer and Lodish, 1994; Hirsch et al., 1998). The fatty liver plays a role in energy storage, and sensitivity to fatty liver varies from species to species (Hermier et al., 2003). Higher levels of expression of the FATP1 gene and higher levels of protein and fat content in the Mini chicken support our assumption that the FATP1 gene could be a candidate gene for fat deposition.

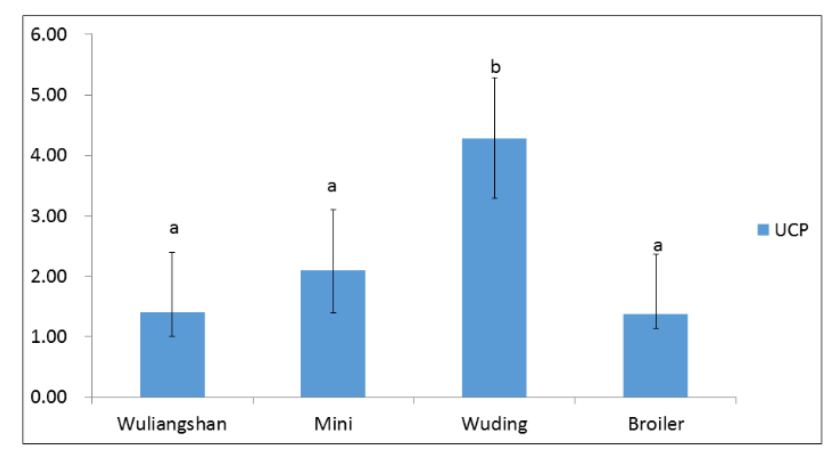

Figure 2. Changes of different chicken breeds' muscle UCP gene mRNA expression: Photographs showing qPCR analysis of UCP expression of three native chickens and one broiler at the age of 20 weeks. Wuding chickens had higher gene expression. Data are presented as means \pm standard error. The difference marked with lowercase letters indicate significant differences $(\mathrm{P}<0.05)$.

PPAR-a gene expression (Peroxisome ProliferatorActivated Receptor): The PPAR receptors comprise 3 family isotype members: $\alpha, \beta$, and $\gamma$ (Desvergne et al., 1998). $\operatorname{PPAR} \alpha, \beta$, and $\gamma$ were previously recognized in the regulatory regions of different genes that were concerned with lipid metabolism and energy balances (Desvergne and Wahli, 1995). As previously indicated, various isotypes of PPAR have special effects on lipid metabolism, and n-3 and n-6 fatty acids with different potencies motivate these PPAR isotypes. So, PPAR $\alpha$, which n-3 and n-6 fatty acids activate to a greater extent, has the greater potency to activate peroxisomal enzymes (Power and Newsholme, 1997). The present experiment provides evidence that PPAR- $\alpha$ plays an important role in lipid metabolism. Our study found a significant breed difference in PPAR $-\alpha$ expression: we noticed the highest $(\mathrm{P}<0.05)$ PPAR- $\alpha$ expression in the Wuding followed by the Mini, and Wuliangshan, while the lowest expression levels pointed to the broiler (Fig. 3). There was a significant difference between the Wuding and Mini chicken, but both had higher levels of expression. Moreover, there was no significant difference between the Wuliangshan and the broiler chicken. Peroxisome proliferator-activated receptor- $\alpha$ (PPAR- $\alpha$ ) increased fatty acid (FA) oxidation by up-regulating the expression of the carnitine palmitoyltransferase enzymes and acyl-coenzyme A (CoA) oxidase (ACO) (Savory et al., 1998; Torra et al., 1999). In our 
study, fat contents also increased and gene expression was higher in the Wuding and Mini chicken. This demonstrated a positive relationship between PPAR- $\alpha$ and fat contents suggested that PPAR- $\alpha$ could play a prominent role in IMF deposition.

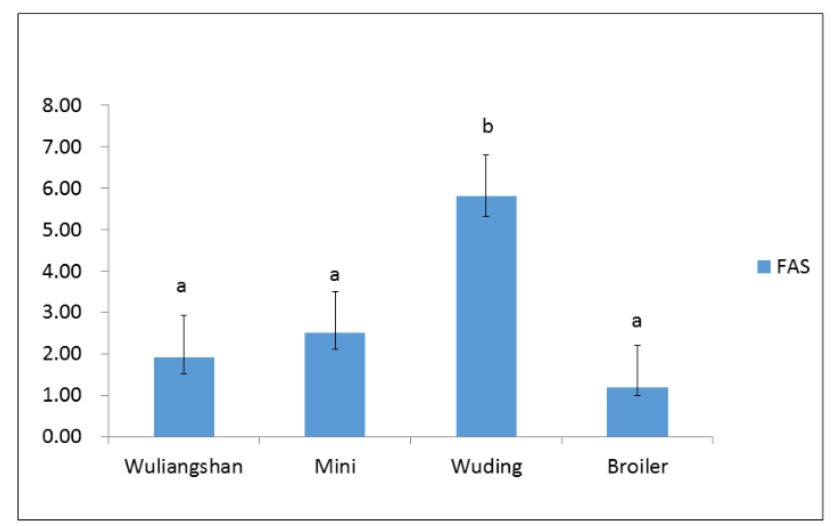

Figure 3. Changes of different chicken breeds' muscle FAS gene mRNA expression: Photographs showing qPCR analysis of FAS expression of three native chickens and one broiler at the age of 20 weeks. Wuding chickens had higher gene expression. Data are presented as means \pm standard error. The difference marked with lowercase letters indicate significant differences $(\mathrm{P}<0.05)$.

UCP gene expression: The uncoupling protein (UCP) gene has four family members in the mammal class (Ricquier and Bouillaud, 2000). Moreover, chicken has only one family member that has been cloned (Ricquier, 2001). It is known from previous studies that the UCP gene has been moderately implicated in obesity (Fleury et al., 1997; Ricquier and Bouillaud, 2000). Additionally, through the regulation of leptin, the UCP gene can produce the obesity gene, which plays a critical role in energy intake and expenditure (Kim and Baik, 2004). Keeping in mind all these studies, the UCP gene could be a candidate gene for affecting fat metabolism in different breeds. We studied the UCP gene expression in four different breeds; the results showed that differed from each other to an extremely large extent. The Wuding experienced a higher gene expression level $(\mathrm{P}<0.05)$, then the Mini, Wuliangshan, and broiler (Fig. 4). The muscle expression of the Mini, Wuliangshan, and broiler did not differ significantly. However, the Mini chicken's muscle expression was higher than the Wuliangshans and the broilers. Previously, different studies on UCP gene expression levels in chicken showed differential levels of gene expression. Studies on the Isoland chicken lines showed that the Isoland chicken had 1.3-fold higher gene expression while 30-40\% higher food consumption with a lower food conversion rate than chicken lines that had similar body weights and egg production (Evock-Clover et al., 2002). Due to the significant role of the UCP gene in energy metabolism, and body temperature regulation (Ricquier and Bouillaud, 2000), Evock-Clover et al. (2002) observed in a further study that the layer demonstrated a greater level of expression of the UCP gene than the broiler with each week of age while they were being fed on similar commercial broiler feed. This might be an indication that the UCP gene plays an important role in the energy metabolism of chicken and could be a candidate gene for body fatness traits. Higher expressions of the UCP gene and higher fat contents in the thigh muscles of the Wuding chicken confirm that the UCP gene has some effects on fat metabolism.

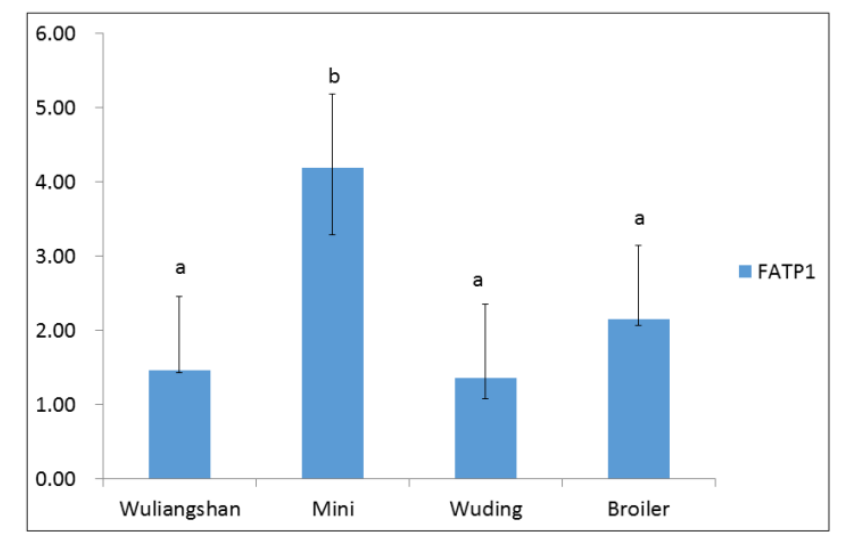

Figure 4. Changes of different chicken breeds' muscle FATP1 gene mRNA expression: Photographs showing qPCR analysis of FATP1 expression of three native chickens and one broiler at the age of 20 weeks. MINI chickens had higher gene expression. Data are presented as means \pm standard error. The difference marked with lowercase letters indicate significant differences $(\mathrm{P}<0.05)$.

FAS gene expression: The present experimental results showed that there were significantly high differences $(\mathrm{P}<0.05)$ in FAS gene expression between the Wuding, Mini, Wuliangshan, and broiler chicken. The expression level was also higher in the Mini and Wuliangshan than it was in the broiler, but this difference was not significant. Furthermore, the IMF contents of the former breed were higher $(\mathrm{P}<0.01)$ than those of the latter. In birds and mammals, fatty acid synthase (FAS) is a multifunctional enzyme that plays an essential role in the biosynthesis of long-chain fatty acids by catalyzing the conversion of acetyl-CoA and malonyl-CoA to palmitate (Wakil et al., 1983). In pigs' adipose tissues, the FAS gene correlated positively with the carcass weight of adipocyte $(\mathrm{P}<0.01)$ (Wenzhong et al., 2001). Chen et al. (2004) observed in pigs that the gene expression ratio correlated highly and positively with IMF content $(\mathrm{P}<0.01)$. Moreover, Dridi et al. (2005) found significantly higher 
plasma leptin levels and FAS gene expression in high-fat line chickens than in low-fat line chickens $(\mathrm{P}<0.05)$. All these studies suggested that the FAS gene participates in fat accumulation and plays an important role in buildup of IMF. There are a few studies regarding the IMF characteristic. Regarding gene expression in chickens, our results concerning the expression of the FAS gene here can add to existing knowledge on the developmental expression pattern of FAS mRNA and facilitate further research on the molecular mechanisms and IMF deposition in chicken.

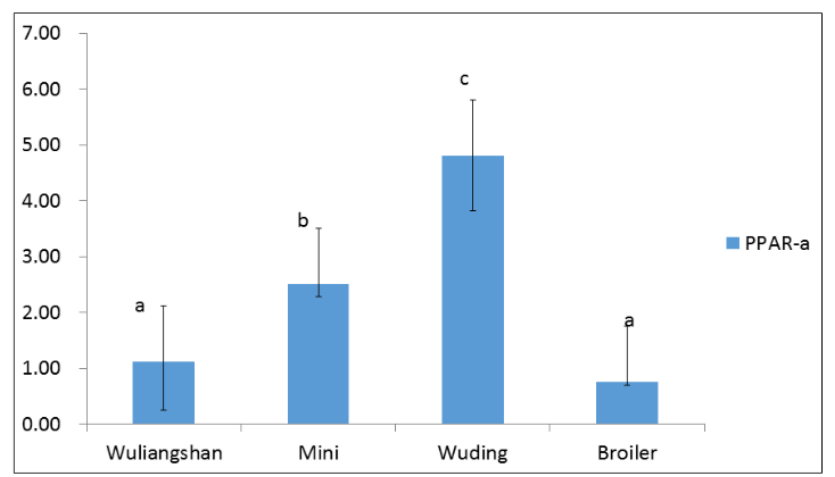

Figure 5. Changes of different chicken breeds' muscle PPAR-a gene mRNA expression: Photographs showing qPCR analysis of PPAR-a expression of three native chicken and one broiler at the age of 20 weeks. Wuding chickens had higher $(P<0.05)$ gene expression followed by mini chicken $(\mathbf{P}<\mathbf{0 . 0 5})$ then Wuliangshan and Mini. Data are presented as means \pm standard error. The difference marked with lowercase letters indicate significant differences $(\mathrm{P}<0.05)$.

Conclusions: The analysis of the expression of fat metabolism-related genes produced equivalent patterns: in general, the Wuding and Mini showed higher expression levels, whereas the Wuliangshan and broiler showed the lowest levels of expression. The higher expressions of the LPL, UCP, FAS and PPAR genes were evident in the Wuding chicken, whereas the Mini chicken experienced a higher expression of the FATP1 gene than all the other breeds. PPAR expression was also higher in the Mini chicken than in the Wuliangshan and broiler, while the Wuliangshan and broiler showed the lowest expression of all the aforementioned genes. Owing to these similar patterns of gene expression with respect to chemical composition, the lowest IMF content was observed in the broiler. In the thigh muscles, the Wuding chicken had highest IMF content followed by the Mini chicken, whereas the Mini chicken had higher crude protein and ash content followed by the Wuding chicken. In breast muscle, the Wuliangshan had higher crude fat, protein, and ash content followed by the Wuding and Mini chicken. According to the present results, the native breeds had higher
IMF and gene expression than the broiler. Consequently, it seems that related genes partially regulate IMF deposition in chickens. These findings provide meaningful information and contribute to the development of a basis for further research that will explain the molecular mechanisms underlying IMF deposition in chicken.

Acknowledgments: This work was supported by the national natural science foundation research project (U1702232, 31260532; 31560618 and 31572359). Yunnan science and technology key project (2016FA046). Yunnan Agriculture University: for their valuable suggestions and support of manuscript.

\section{REFERENCES}

Anderson, F., L. Pannier, D. Pethick and G. Gardner. 2015. Intramuscular fat in lamb muscle and the impact of selection for improved carcass lean meat yield. Animal 9:1081-1090.

AOAC. 2011. Official methods of analytical chemist, $18^{\text {th }} \mathrm{Ed}$. Gaithersburg, MD: Association of Official Analytical Chemists, USA.

Beisiegel, U. and J. Heeren. 1997. Lipoprotein lipase (ec 3.1. 1.34) targeting of lipoproteins to receptors. Proc. Nutr. Soc. 56:731-737.

Bensadoun, A. 1991. Lipoprotein lipase. Ann. Rev. Nutr. 11:217-237.

Berri, C., N. Wacrenier, N. Millet and E. Le Bihan-Duval. 2001. Effect of selection for improved body composition on muscle and meat characteristics of broilers from experimental and commercial lines. Poult. Sci. 80:833838 .

Binnert, C., H.A. Koistinen, G. Martin, F. Andreelli and P. Ebeling, V.A. Koivisto, M. Laville, J. Auwerx and H. Vidal. 2000. Fatty acid transport protein-1 mrna expression in skeletal muscle and in adipose tissue in humans. Am. J. Physiol. Endocrinol. Metab. 279:E1072E1079.

Castellini, C., C. Mugnai and A. Dal Bosco. 2002. Effect of organic production system on broiler carcass and meat quality. Meat Sci. 60:219-225.

Chen, J., X.J. Yang, H. Tong and R.Q. Zhao. 2004. Expressions of fas and hsl mrna in longissimus dorsi muscle and their relation to intramuscular fat contents in pig. J. Agric. Biotechnol. 12:422-426.

Chinese Chicken Feeding Standard. 2004. First edition. National Agricultural Ministry Press, Bejing.

Choe, J.H., K.C. Nam, S. Jung, B.N. Kim, H.J. Yun and C.R. Jo. 2010. Differences in the quality characteristics between commercial korean native chickens and broilers. Kor. J. Food Sci. Anim. Resour. 30:13-19.

Christoffersen, N., R. Shalgi, L. Frankel, E. Leucci, M. Lees, M. Klausen, Y. Pilpel, F. Nielsen, M. Oren and A.H. Lund. 
2010. P53-independent upregulation of mir-34a during oncogene-induced senescence represses MYC. Cell Death Differ. 17:236-245.

Cui, H.X., R.R. Liu, G.P. Zhao, M.Q. Zheng, J.L. Chen and J. Wen. 2012. Identification of differentially expressed genes and pathways for intramuscular fat deposition in pectoralis major tissues of fast-and slow-growing chickens. BMC Genomics 13:213.

Davail, S., G. Guy, J.M. André, D. Hermier and R. Hoo-Paris. 2000. Metabolism in two breeds of geese with moderate or large overfeeding induced liver-steatosis. Comp. Biochem. Physiol. A. Mol. Integr. Physiol. 126:91-99.

Desvergne, B., A. Ijpenberg, P.R. Devchand and W. Wahli. 1998. The peroxisome proliferator-activated receptors at the cross-road of diet and hormonal signalling. J. Steroid Biochem. Mol. Biol. 65:65-74.

Desvergne, B. and W. Wahli. 1995. Ppar: A key nuclear factor in nutrient/gene interactions? In: Inducible gene expression. Birkhauser Boston; pp.142-176.

Dikeman, M., E. Pollak, Z. Zhang, D. Moser, C. Gill and E. Dressler. 2005. Phenotypic ranges and relationships among carcass and meat palatability traits for fourteen cattle breeds, and heritabilities and expected progeny differences for warner-bratzler shear force in three beef cattle breeds. J. Anim. Sci. 83:2461-2467.

Dodson, M.V., Z. Jiang, J. Chen, G.J. Hausman, L.L. Guan, J. Novakofski, D.P. Thompson, C.L. Lorenzen, M.E. Fernyhough and P.S. Mir. 2010. Allied industry approaches to alter intramuscular fat content and composition in beef animals. J. Food Sci. 75:1-8.

Doege, H. and A. Stahl. 2006. Protein-mediated fatty acid uptake: Novel insights from in vivo models. Physiol. 21:259-268.

Dridi, S., J. Buyse, E. Decuypere and M. Taouis. 2005. Potential role of leptin in increase of fatty acid synthase gene expression in chicken liver. Domest. Anim. Endocrinol. 29:646-660.

Du, M., J. Yin and M.J. Zhu. 2010. Cellular signaling pathways regulating the initial stage of adipogenesis and marbling of skeletal muscle. Meat Sci. 86:103-109.

Evock-Clover, C.M., S.M. Poch, M.P. Richards, C.M. Ashwell and J.P. McMurtry. 2002. Expression of an uncoupling protein gene homolog in chickens. Comp. Biochem. Physiol. A. Mol. Integr. Physiol. 133:345-358.

Fanatico, A., P. Pillai, L. Cavitt, C. Owens and J. Emmert. 2005. Evaluation of slower-growing broiler genotypes grown with and without outdoor access: Growth performance and carcass yield. Poult. Sci. 84:1321-1327.

Fernandez, X., G. Monin, A. Talmant, J. Mourot and B. Lebret. 1999. Influence of intramuscular fat content on the quality of pig meat-1. Composition of the lipid fraction and sensory characteristics of $\mathrm{m}$. longissimus lumborum. Meat Sci. 53:59-65.

Fleury, C., M. Neverova, S. Collins, S. Raimbault, O. Champigny, C. Levi-Meyrueis, F. Bouillaud, M.F. Seldin, R.S. Surwit and D. Ricquier. 1997. Uncoupling protein2: A novel gene linked to obesity and hyperinsulinemia.
Nat. Genet. 15:269-272.

Geldenhuys, G., L.C. Hoffman and N. Muller. 2013. The effect of season, sex, and portion on the carcass characteristics, $\mathrm{pH}$, color, and proximate composition of egyptian goose (alopochen aegyptiacus) meat. Poult. Sci. 92:3283-3291.

Griffin, H., S. Butterwith and C. Goddard. 1987. Contribution of lipoprotein lipase to differences in fatness between broiler and layer-strain chickens. Br. Poult. Sci. 28:197206.

Guo, J., T. Shan, T. Wu, L. Zhu, Y. Ren, S. An and Y. Wang. 2011. Comparisons of different muscle metabolic enzymes and muscle fiber types in jinhua and landrace pigs. J. Anim. Sci. 89:185-191.

Hatch, G.M., A.J. Smith, F.Y. Xu, A.M. Hall and D.A. Bernlohr. 2002. Fatp1 channels exogenous fa into 1, 2, 3triacyl-sn-glycerol and down-regulates sphingomyelin and cholesterol metabolism in growing 293 cells. J. Lipid Res. 43:1380-1389.

Hermier, D., M.J. Chapman and B. Leclercq. 1984. Plasma lipoprotein profile in fasted and refed chickens of two strains selected for high or low adiposity. J. Nutr. 114:1112-1121.

Hermier, D., G. Guy, S. Guillaumin, S. Davail, J.-M. André and R. Hoo-Paris. 2003. Differential channelling of liver lipids in relation to susceptibility to hepatic steatosis in two species of ducks. Comp. Biochem. Physiol. B. Biochem. Mol. Biol. 135:663-675.

Hirsch, D., A. Stahl and H.F. Lodish. 1998. A family of fatty acid transporters conserved from mycobacterium to man. Proc. Natl. Acad. Sci. 95:8625-8629.

Hocquette, J.-F., B.t. Graulet and T. Olivecrona. 1998. Lipoprotein lipase activity and mrna levels in bovine tissues. Comp. Biochem. Physiol. B. Biochem. Mol.Biol. 121:201-212.

Hu, H., J. Wang, R. Zhu, J. Guo and Y. Wu. 2008. Effect of myosin heavy chain composition of muscles on meat quality in Laiwu pigs and Duroc. Sci. China Ser. C Life Sci. 51:127-132.

Huda, N., A. Putra and R. Ahmad. 2011. Proximate and physicochemical properties of peking and muscovy duck breasts and thighs for further processing. J. Food Agric. Environ. 9:82-88.

Jaturasitha, S., T. Srikanchai, M. Kreuzer and M. Wicke. 2008. Differences in carcass and meat characteristics between chicken indigenous to northern thailand (black-boned and thai native) and imported extensive breeds (bresse and rhode island red). Poult. Sci. 87:160-169.

Kim, K. and M. Baik. 2004. Production of leptin in E. coli and its effect on glucose and acetate transport and expression of uncoupling protein-2 gene in adipose tissues of korean cattle (hanwoo). Asian Australasian J. Anim. Sci. 17:1062-1068.

Kouba, M., D. Hermier and M.A. Bernard-Griffiths. 1995. Comparative study of hepatic vldl secretion in vivo in the growing turkey (meleagris gallopavo) and chicken (gallus domesticus). Comp. Biochem. Physiol. B. 
Biochem. Mol. Biol. 110:47-55.

Lewis, P., G. Perry, L. Farmer and R. Patterson. 1997. Responses of two genotypes of chicken to the diets and stocking densities typical of uk and 'label rouge'production systems: I. Performance, behaviour and carcass composition. Meat Sci. 45:501-516.

Liu, F. and Z. Niu. 2008. Carcass quality of different meattyped chickens when achieve a common physiological body weight. Intl. J. Poult. Sci. 7:319-322.

Lobo, S., B.M. Wiczer, A.J. Smith, A.M. Hall and D.A. Bernlohr. 2007. Fatty acid metabolism in adipocytes: Functional analysis of fatty acid transport proteins 1 and 4. J. lipid Res. 48:609-620.

Mead, J.R., S.A. Irvine and D.P. Ramji. 2002. Lipoprotein lipase: Structure, function, regulation, and role in disease. J. Mol. Med. 80:753-769.

Moreno-Sánchez, N., J. Rueda, M.J. Carabaño, A. Reverter, S. McWilliam, C. González and C. Díaz. 2010. Skeletal muscle specific genes networks in cattle. Funct. Integr. Genomics 10:609-618.

Moynihan, K.A. and S.I. Imai. 2006. Sirt1 as a key regulator orchestrating the response to caloric restriction. Drug Disc.Today Dis. Mech. 3:11-17.

Nechtelberger, D., V. Pires, J. Söolknet, G. Brem, M. Mueller and S. Mueller. 2001. Intramuscular fat content and genetic variants at fatty acid-binding protein loci in austrian pigs. J. Anim. Sci. 79:2798-2804.

NRC. 1994. Nutrient requirements of poultry. National Research Council. Natl. Acad. Press Washington, USA.

Pohl, J., A. Ring, T. Hermann and W. Stremmel. 2004. Role of fatp in parenchymal cell fatty acid uptake. Biochimica et Biophysica Acta (BBA)- Mol. Cell Biol. Lipids. 1686:1-6.

Power, G.W. and E.A. Newsholme. 1997. Dietary fatty acids influence the activity and metabolic control of mitochondrial carnitine palmitoyltransferase $i$ in rat heart and skeletal muscle. J. Nutr. 127:2142-2150.

Ren, M., J. Wegner, O. Bellmann, G. Brockmann, F. Schneider, F. Teuscher and K. Ender. 2002. Comparing mRNA levels of genes encoding leptin, leptin receptor, and lipoprotein lipase between dairy and beef cattle. Domest. Anim. Endocrinol. 23:371-381.

Ricquier, D. 2001. Le transporteur mitochondrial ucp2: Rôle dans l'immunité non spécifique et la production des ions superoxide. Med Sci. 107-108.
Ricquier, D. and F. Bouillaud. 2000. The uncoupling protein homologues: UCP1, UCP2, UCP3, StUCP and AtUCP. Biochem. J. 345:161-179.

Ros-Freixedes, R., J. Reixach, L. Bosch, M. Tor and J. Estany. 2014. Genetic correlations of intramuscular fat content and fatty acid composition among muscles and with subcutaneous fat in duroc pigs. J. Anim. Sci. 92:54175425.

Sato, K., Y. Akiba, Y. Chida and K. Takahashi. 1999. Lipoprotein hydrolysis and fat accumulation in chicken adipose tissues are reduced by chronic administration of lipoprotein lipase monoclonal antibodies. Poult. Sci. 78:1286-1291.

Savory, R., N.J. Horley, A.I. Choudhury, M. Dickins, J. Tim and A.M. Salter. 1998. Molecular basis of nonresponsiveness to peroxisome proliferators: The guineapig ppara is functional and mediates peroxisome proliferator-induced hypolipidaemia. Biochem. J. 332:689-693.

Schaffer, J.E. and H.F. Lodish. 1994. Expression cloning and characterization of a novel adipocyte long chain fatty acid transport protein. Cell 79:427-436.

Shan, T., Y. Wang, Y. Liu, J. Liu, J. Feng and Z. Xu. 2006. Developmental expression of the lipoprotein lipase gene in porcine subcutaneous adipose tissue. J. Anim. Feed Sci. 15:621-629.

Torra, I.P., P. Gervois and B. Staels. 1999. Peroxisome proliterator-activated receptor alpha in metabolic disease, inflammation, atherosclerosis and aging. Curr. Opin. Lipidol. 10:151-160.

Wakil, S.J., J.K. Stoops and V.C. Joshi. 1983. Fatty acid synthesis and its regulation. Annu. Rev. Biochem. 52:537-579.

Wenzhong, X., Y. Feng and Z. Anguo. 2001. Study of regulation of exogenous recombiant somatotropin on fat metabolism in different cross-finishing pigs. Acta Veterin. et Zootechnica Sinica 32:1-4.

Yang, N. and R.-S. Jiang. 2005. Recent advances in breeding for quality chickens.World's Poult. Sci. J. 61:373-381.

Zhao, X., D. Mo, A. Li, W. Gong, S. Xiao, Y. Zhang, L. Qin, Y. Niu, Y. Guo and X. Liu. 2011. Comparative analyses by sequencing of transcriptomes during skeletal muscle development between pig breeds differing in muscle growth rate and fatness. PloS One 6:e19774. 